\title{
O ABRIGO DE INFORMAÇÕES ASCENDENTES NA REGIÃO DE CAMPINAS: AS RÁDIOS LIVRES E A VERSÃO PERIFÉRICA DA DINÂMICA URBANA ${ }^{1}$
}

\author{
CRISTIANO Nunes Alves ${ }^{2}$ \\ Universidade de Campinas
}

Resumo: Buscamos analisar as dinâmicas socioterritoriais na cidade de Campinas, destacando a circulação de informações. Com este intuito, pretendemos contribuir para o entendimento do circuito em torno das rádios livres nesta região. A dinâmica deste circuito radiodifusor FM implica o uso de objetos técnicos - desde transmissores, até antenas de rádio - e um considerável número de ações, que fazem circular espessuras ascendentes por toda a urbe. Nosso inventário demonstra que as rádios livres são abrigadas nas periferias de Campinas e das cidades de seu entorno. Tais emissoras agem de uma maneira alternativa aos padrões impostos pelas grandes empresas de informação, sinalizando para táticas de resistência cultural, a partir da difusão, na maioria dos casos, de uma produção fonográfica lugarizada. Indagamo-nos sobre as possibilidades de melhor articular a comunicação na metrópole atual, lugar de diferentes temporalidades.

Palavras-chave: Campinas; Território; Rádios livres; Periferia urbana; Informação ascendente.

\section{REFUGE OF RISING INFORMATIONS IN CAMPINAS: THE FREE RADIOS AND THE PERIPHERAL VERSION OF URBAN DYNAMICS}

Abstract: We analyze the socio-territorial dynamics in the city today, highlighting the flow of information. We intend thus to contribute to the understanding of the circuit of information associated with the free radios in the region of Campinas-SP. The dynamics of this circuit of FM radio implies the use of technical objects, from transmitters to radio antennas, and a considerable

\footnotetext{
${ }^{1}$ Versão alterada do texto apresentado no IV Seminário Metrópoles: Governo, Sociedade e Território Metrópoles dos Invisíveis e Ação Social. Que ocorreu nos dias 1,2 e 3 de outubro de 2013, na cidade de São Gonçalo - RJ.

${ }^{2}$ Integrante do Laboratório GEOPLAN, no Departamento de Geografia da Universidade Estadual de Campinas. Contato: cris7cris7@yahoo.com.br.
} 
number of actions, which allows information circulate throughout the city. Our inventory shows that the free radios are sheltered in the peripheries of the city of Campinas and its surroundings. The seasons act in a way as alternative to the standards imposed by major media corporations, signaling tactics of cultural resistance and diffusing, in most cases, a phonographic production rooted in the places. We interrogate our selves about the possibilities for improving communication in today's metropolis, a place of different temporalities.

Keywords: Campinas; territory, free radios, urban periphery, arising information.

\section{Introdução}

Com significativa densidade técnico-informacional e entre as cidades mais importantes do Estado de São Paulo, Campinas abriga atualmente 1.154.617 habitantes (Instituto Brasileiro de Geografia e Estatística - IBGE, estimativa 2014). Caracterizada pela desigualdade socioterritorial, a cidade é núcleo da Região Metropolitana de Campinas (RMC), composta por 19 municípios. Importante elo informacional, polo industrial e tecnológico intensamente ligado à metrópole paulistana ${ }^{3}$, Campinas possui também um pulsante circuito de rádios livres.

A dinâmica do circuito sonoro em torno das rádios livres campineiras implica o uso dos objetos técnicos de informação - rádios, receptores de rádio, antenas de transmissão e até telefones celulares - e fixos geográficos, tais quais estúdios fonográficos, entre outros. Sua dinâmica engloba, ainda, as mediações cotidianas das experiências relacionadas à radiodifusão, a saber: associações e conflitos presentes nas ações dos militantes comunicacionais e em suas inúmeras articulações acolhidas no espaço urbano.

Partimos da ideia de que a existência e a dinâmica de um circuito ganham significado quando são analisadas as estratégias políticas no território usado. Nossa categoria de análise, sinônimo de concretude de sistemas de objetos e sistemas de

\footnotetext{
${ }^{3}$ Em Campinas localizam-se consideráveis densidades técnicas e informacionais ligadas à inovação e a setores estratégicos da economia, presentes seja em suas universidades, no Instituto Agronômico de Campinas (IAC), na Refinaria de Petróleo de Paulínia (REPLAN), no Centro de Pesquisa e Desenvolvimento em Telecomunicações (CPqD), no Centro Tecnológico para Informática (CTI), ou em outros. A RMC, atualmente com 2.866.453 habitantes (Estimativa - IBGE, 2012), abriga um diversificado parque industrial que compreende desde indústrias têxteis e um espesso setor terciário, até setores de alta tecnologia ligados à química, à eletrônica, à mecânica e às telecomunicações. Ao mesmo tempo, o crescimento da Região, sobretudo nos últimos vinte anos, vem aprofundando uma série de problemas tais quais a favelização e a periferização. Segundo dados do IBGE (2010), em Campinas, cerca de 150 mil pessoas (14\% da população) vivem em "aglomerações subnormais" (favelas, barracos ou invasões), situadas em especial na zona sul da cidade, fenômeno que se estende a boa parte dos municípios vizinhos. Nesse sentido Cano e Brandão (2002, p. 124) afirmam que a evolução da mancha urbana campineira "sempre esteve articulada a interesses da elite local", tendo a legislação urbanística, os mecanismos de especulação e orçamentos públicos comprometidos com grandes empresas, o que leva à formação de um espaço urbano fragmentado e segregado.
} 
ações no espaço geográfico, apontam para situações específicas. Segundo Santos (2004, p. 232): "A utilização do território pelo povo cria o espaço" e o território,

(...) se chama espaço logo que encarado segundo a sucessão histórica de situações de ocupação efetiva por um povo inclusive a situação atual - como resultado da ação de um povo, do trabalho de um povo.

Em Campinas, boa parte dessas rádios livres, as quais denominamos emissoras "não concessionadas", fortalece manifestações culturais lugarizadas, difundindo a música raiz (a chamada moda de viola), a folia de reis, o rap (gênero musical da cultura hip hop), entre outros. Aqui, nos referimos às emissoras que não integram o sistema de concessões conforme o Código Brasileiro de Telecomunicações (Lei ${ }^{\circ}$ 4.117, de novembro de 1962). Dados da Associação Brasileira das Rádios Comunitárias (ABRACO) atestam que estes veículos de comunicação totalizam quase vinte mil emissoras no país. De acordo com Tella (2000, p. 90), são aproximadamente duas mil rádios livres no Estado de São Paulo.

Machado et. al. (1987) propõem que as rádios livres inovam e trazem a comunicação ao passo que eliminam intermediários e comentaristas, deixando que os "acontecimentos sejam reportados pelos seus próprios personagens" (1987, p. 30), de um modo ruidoso e desconcertante com "acentos locais e sotaques plebeus" (p. 30). Por meio das rádios livres são disseminadas mensagens de conscientização, história e valores da cultura dos lugares, são organizados e divulgados eventos, abordados problemas dos bairros, como a carência de bens e serviços públicos, entre outros, tornando-se estes meios de informação, verdadeiros prestadores de serviços públicos, ao fomentarem a comunicação nos lugares e entre os lugares.

Ao mesmo tempo, estas emissoras livres enfrentam grande repressão por parte das autoridades. Isso porque, no caso da radiodifusão, prevalece o interesse de quem tem a norma consigo, uma vez que a legislação brasileira trata como crime contra a segurança nacional qualquer emissão de rádio não autorizada. A repressão às rádios livres fundamenta-se no limite de frequência disponível no espectro radiofônico e nas interferências, este último argumento é o mais utilizado pela ANATEL (Agência Nacional de Telecomunicações), órgão responsável pela regulação do setor radiofônico. Conforme esclarece Andriotti (2004), existem inúmeras controvérsias em torno da questão, o discurso técnico se sobrepõe à discussão a respeito dos usos dessas rádios, configurando-se numa maneira de justificar apreensões em série ${ }^{4}$, muitas delas a ferir a Constituição Federal, atitude

\footnotetext{
${ }^{4}$ Segundo Andriotti (2004), no período entre 1998-2002 foram aproximadamente 10.100 os inquéritos abertos e 3.633 os indivíduos indiciados, além de uma série de equipamentos apreendidos (Fonte:
} 
que já implicou alguns processos judiciais contra o órgão regulador.

Mattelart (2002) entende que o modelo difusionista traz consigo uma comunicação persuasiva, enquanto Cohn (1973) alerta em seus estudos sobre a difusão de inovações, que a comunicação não faz parte desta dimensão, tratada que é, como mera infraestrutura, o que negligencia os processos que a constituem.

As emissoras livres - chamadas ainda de alternativas, comunitárias, genéricas ou participativas - contestam o modelo público e privado instituído na radiodifusão. Assim como questionam a sua programação uniformizante, latentemente surda para o que diz a maioria, por ser uma programação

(...) comercialmente viável, determinada por especialistas em atrair grandes públicos, programas padronizados, planejados e realizados somente por jornalistas, redatores, produtores, apresentadores e disc-jóqueis profissionais (AMAYO, 1992, p. 61).

Ora, em Campinas predomina a difusão em rede no circuito de rádio FM concessionado e a preponderância da publicidade como elo entre a radiodifusão e o registro fonográfico local, cujo repertório musical praticamente não faz parte das programações. Tais redes são controladas por grandes grupos de informação, vinculadores de conteúdos e/ou detentores de emissoras (ALVES, 2008). Nessa via, Lopes (1997, p. 325) lembra que no Brasil o sistema de concessões para radiodifusão é "extremamente autoritário e concentrado", com pouquíssimas exigências para a escolha do concessionário e sem qualquer impedimento à formação de oligopólios ou monopólios.

No presente trabalho em torno das rádios livres na Região de Campinas, propomos uma reflexão sobre os circuitos informacionais nas cidades. Após a apresentação de nossa metodologia de pesquisa, problematizamos a questão da circulação de informações nos lugares e enfocamos os nexos entre o uso do território, a radiodifusão e as associações e conflitos entre as informações descendentes, controladas pelo Estado e pelas grandes corporações e as "informações ascendentes" que, enraizadas nos lugares, fundadas no "dilema da sobrevivência", expressam uma "pluralidade de meios e agentes" reorganizadores de informações de diversas naturezas "mais destinadas à construção da cidadania e à produção de um sentido político-cultural" (SILVA, 2010, p. 27).

No momento posterior, analisamos alguns aspectos do nosso inventário a respeito das rádios livres campineiras, expondo a relação desses veículos com a

Ministério da Justiça, Departamento da Polícia Federal). Calcula-se para o país um montante em material apreendido em rádios não concessionadas de 130 milhões de reais, o que nos dá ideia das ações de fechamento das emissoras (ABRACO). 
dinâmica das periferias de Campinas. A informação e a comunicação têm capacidade de ordenação social e, assim, guardam "uma função política no sentido da constituição ou formação da pólis" (SODRÉ, 1976, p. 19), ou seja, são entes de fundamental importância no contexto urbano contemporâneo. Daí a nossa inquietude para com a compreensão do papel da comunicação no período em curso e o enfoque nas rádios livres.

Com a proposta de esmiuçar a radiodifusão, as informações ascendentes e o movimento do território a partir da noção de circuito, visamos melhor compreender a situação concreta resultante do processo de espacialização de normas, materialidades, ações e formas, que a partir dos usos mediados pela técnica, configuram o espaço geográfico e os seus lugares em Campinas.

\section{A metodologia de pesquisa}

A operacionalização desta pesquisa compreendeu um levantamento bibliográfico em monografias, dissertações, teses, livros e periódicos sobre a questão, envolvendo estudos realizados no âmbito da Geografia e nas demais Ciências Humanas, como a História e a Antropologia. Nessa via, abarcamos os seguintes eixos temáticos: 1) uso do território; 2) comunicação e informação; 3) radiodifusão; 4) rádios livres e mídia alternativa; 5) urbanização e periferização em Campinas.

Ainda como parte de nosso levantamento, realizamos a coleta de dados e informações junto a órgãos como o Serviço Social do Comércio (SESC), a Fundação Sistema Estadual de Análise de Dados (SEADE), a Empresa Paulista de Planejamento Metropolitano (EMPLASA), o IBGE, a Agência Nacional de Telecomunicações (Anatel), a Associação Brasileira de Emissoras de Rádio e Televisão (ABERT), o Instituto Fernand Braudel, o Centro de Mídia Independente (CMI), a Associação Brasileira de Rádios Comunitárias (ABRACO), a Associação Brasileira de Música Independente (ABMI), a Secretaria de Planejamento de Campinas (SEPLAMA), a Secretaria de Cultura e Lazer do Município de Campinas, o Arquivo do Jornal Correio Popular - Campinas, o Arquivo do Jornal Todo Dia - Americana, além de consultas a sítios da internet e a panfletos e zines relacionados às mídias alternativas na Região de Campinas.

Igualmente compondo o escopo de nossa metodologia de pesquisa, uma série de trabalhos de campo que desenvolvemos. Reunimos, desta forma, um importante “campo de informação primário" resultante de 13 entrevistas semiestruturadas e 15 visitas técnicas. Quanto às entrevistas, tratou-se de uma espécie de diálogos na qual um roteiro maleável se desenvolveu, procurando desvelar os sistemas técnicos, a 
estrutura fixa e os fluxos embutidos na dinâmica do circuito das rádios livres. Entrevistou-se assim, agentes ligados à temática (trabalhadores culturais, tais quais locutores e anunciantes; membros do poder público, entre outros). Por outro lado, realizaram-se visitas técnicas a lugares conformados ou apropriados por esse circuito (emissoras de rádio, centrais de transmissão, estúdios caseiros de áudio, entre outros). Tais informações encontram-se no texto acompanhadas por um asterisco, como este: *.

As ações repressoras contra os agentes que dinamizam as rádios livres provocam a dificuldade em conseguir informações mais apuradas sobre o circuito devido ao receio de seus integrantes, que estão atentos sobre o que falar e com quem falar para que não haja represálias. Tivemos que lidar com tal questão em nossos trabalhos de campo, obstáculo transposto por meio de uma troca transparente de informações com os agentes do circuito. Esta postura resultou em incursões nas periferias de Campinas na rota das rádios livres, conhecida pelos militantes comunicacionais como Eletromagnetur*, trajetória abrigada, sobretudo, na zona sul campineira, e que norteou nossas saídas a campo.

\section{O meio esquizofônico, a radiodifusão e os circuitos informacionais descendentes: as inovações e a padronização sonora dos lugares}

Desde o telégrafo e, pouco depois, com o rádio e o registro fonográfico, delineia-se o fenômeno da esquizofonia (SCHAFER, 1997), que se refere ao rompimento entre a origem e a emissão sonora, fato inserido num conjunto de transformações de sistemas técnicos que compreende, ainda, o cinema. São dados ativos que constituem e impulsionam uma revolução no tempo livre (FRIEDMANN, 1968), dispensando a presença humana para a ação e a transmissão de informações.

Nesse sentido, Schafer (1997, p. 326) pontua a relação entre a empresa do rádio e o controle de informação constituindo circuitos informacionais descendentes, ao afirmar a "tentativa deliberada de regular o fluxo de informações de acordo com as respostas e as capacidades de processamento de informações humanas" posta pela transmissão via ondas. $\mathrm{O}$ autor supracitado afirma a importância do estudo dos sons inseridos em seus contextos, constituindo eventos que em sua interação e simultaneidade formam uma dada espacialização, que é chamada de paisagem sonora "um campo de interações mesmo quando particularizada dentro dos componentes de seus eventos sonoros" (SCHAFER, 1997, p. 185). No nexo entre informação e território está a preocupação com as rádios livres, procurando aclarar 
o modo como os próprios lugares produzem informação por meio de circuitos ascendentes.

Carney (1990), Carney e Nash (1996) e Romagnan (2000) destacam, também neste viés, a pertinência do estudo da repartição e da difusão das atividades musicais e sonoras no território, enquanto Chaudoir (2003) defende o estudo da diversificação, difusão e da hierarquia dos fatos sonoros na cidade.

Importa lembrar que o alcance potencialmente ilimitado trazido pela difusão das inovações (HAGERSTRAND, 1952; SÁNCHEZ, 1992) esquizofônicas criou outro corpo de relações entre os lugares, conferindo novas espessuras informacionais à paisagem sonora. A vida urbano-industrial e todo o alastramento das próteses no território de onde é característica, desde então, cria lugares ruidosos, impregnando o meio sonoro que se torna eletroacústico:

Proliferam os meios de produção e reprodução sonora, meios fonomecânicos (o gramofone), elétricos (a vitrola e o rádio), eletrônicos (os sintetizadores). O meio sonoro não é mais simplesmente acústico, mas eletroacústico (WISNIK, 1989, p. 47).

Nesse novo meio verifica-se um considerável equilíbrio no grande capital, perseguido mediante a adoção de inovações que o propiciem agir em simultaneidade, de forma a administrar a variável tempo. Smith (1988, p. 213) explica que esse equilíbrio reside precisamente na capacidade do capital de "se deslocar nas paisagens de maneira sistemática". Ora, parece tratar-se justamente do oferecido pela radiodifusão atrelada ao sistema de concessões brasileiro, mais voltado a dar acesso aos mercados por meio do movimento de circuitos informacionais ascendentes, do que a criar comunicação genuína entre os lugares.

Nessa via, por meio da radiodifusão vinculada às grandes esferas de poder, à cooperação e ao trabalho criativo conjunto, impõem-se formatos e desdobram-se cisões no território. Como bem lembra Ribeiro (1991), no final da ditadura militar já havia se configurado um tipo de poder entrelaçado às esferas política, econômica e cultural da vida brasileira. Este modelo, lembra a autora supracitada, impôs novas redes de influência e controle baseadas nas modernas práticas de informação de massa, reafirmando as tendências à desorganização, ao desenraizamento cultural e à integração incompleta do território.

Não por acaso, Morin $(1979$, p. 85) afirma que o importante é saber "em que medida a estética invalida e informa a vida prática" fornecendo-lhe modelos para 0 cotidiano, difundindo o igual. Dessa forma, segundo Tragtenberg (1991, p. 25), “a música contemporânea também possui o seu código sonoro típico, o seu dialeto, ou seja, seu repertório padrão", uma espécie de constante de informação chamada de 
repertório clichê que em larga medida nos remete às informações descendentes e à densidade informacional invasora dos lugares, conforme Santos (2004). Lucca (2002) assevera que à possibilidade infinita de criação musical contrapõe-se o fato de que:

os elementos musicais estão sendo tratados ou manipulados na maior parte das músicas transmitidas atualmente pela mídia, por uma notável simplicidade, limitação e repetição, constantemente crescentes desde sua atuação em nosso país, mais precisamente desde a década de 60 (LUCCA, 2002, p. 115).

Este autor (2002), em um exame detalhado ${ }^{5}$ da programação do circuito de rádio FM paulistano no ano de 2001, atesta a extrema padronização do conteúdo musical difundido. Entre os índices apresentados, destacam-se os $40 \%$ das músicas do rádio FM terem a duração entre 3'30' e 3'59',; $60 \%$ da programação é de música estadunidense; $60 \%$ da programação é da década de 1990 e $20 \%$ da década de 1980. Daí, Lucca (2002) determina:

Os meios de comunicação de massa têm difundido um repertório limitado, homogêneo e repetitivo nos mais diversos aspectos e elementos musicais, tais como época, duração, local de origem, gênero/estilo, melodia, ritmo, dinâmica, harmonia, contraponto, instrumentação, forma, linguagem, fraseado, articulação. Tal prática se expande e se fortalece gradualmente no Brasil mais precisamente desde a década de 1960 (2002, p. 115).

\section{A densa presença do circuito FM nas grandes cidades brasileiras ${ }^{6}$ nos faz}

\footnotetext{
${ }^{5}$ Em sua análise sobre o produto musical vinculado ao circuito de rádio FM paulistano, Lucca (2002) observou os seguintes elementos: título, compositor, arranjador, intérprete, duração, faixa cronológica, origem, gênero/estilo, idioma, instrumentação, interferência da emissora durante a música, ritmo (compasso e métrica), melodia (intervalos, tessitura, monofonia, polifonia e intérprete), harmonia (complexidade dos acordes, variedade das sequências harmônicas), forma (introdução, solo e terminação), andamento e linguagem (tonalidade e modulação).

${ }^{6}$ Os dados e apontamentos a seguir nos dão ideia da quantidade e complexidade de objetos e ações movimentados em torno da radiodifusão hoje no Brasil. Santos e Silveira (2005, p. 241) destacam que hoje "graças a inovações tecnológicas o Brasil estaria em condições de duplicar o número de emissoras". Estes autores lembram que $42 \%$ do total de emissoras FM concessionadas se concentram no Estado de São Paulo, que abriga 548 delas (21\%). Entre os anos de 1977 e 1999 o número de emissoras de rádio quadruplicou no país: de 711 para 2.986, o segundo maior número de emissoras no mundo, ficando atrás somente dos Estados Unidos. Trata-se do veículo de massa que abrange o maior número de lugares. De acordo com o Ministério das Comunicações, em 2004, dos 4.974 municípios da federação, 1573 abrigavam emissoras de rádio. O território nacional quase em sua totalidade é atingido pela radiodifusão. Magnoni (1999, p. 42) lembra que "o rádio é o veículo de comunicação
} 
indagar o quão eficaz é a "catequese sonora" contemporânea. São nessas aglomerações urbanas que o circuito de radio FM e a produção fonográfica (música, publicidade e notícia) que lhe é vinculada em torno de um repertório médio podem tirar maior proveito da contração, a partir do conteúdo recebido pelo ouvinte e a influência imediata nos circuitos culturais cotidianos.

Em conflito e cooperação com os circuitos informacionais descendentes ligados à radiodifusão, situam-se as rádios livres e toda uma espessura comunicacional atrelada aos lugares, como veremos a seguir.

\section{O tempo lento dos lugares e os circuitos de informações ascendentes: as rádios livres e a informação de baixo pra cima}

Santos (2006) nos fala das ações abrigadas no lugar que, a um só tempo, são constituídas da rigidez do "pensamento único" e elaboradas por um conhecimento indisciplinado, comunicante:

(...) o lugar que é o quadro de uma referenda pragmática ao mundo, é também, o teatro das paixões humanas, responsáveis, através da ação comunicativa, das mais diversas manifestações da espontaneidade e da criatividade! (SANTOS 2006, p. 6).

Geertz (2003, p. 117) alerta que este fruto do convívio, dentro de cada vivência específica, redunda no "impulso que serve de base para a construção dos subúrbios: um desejo de tornar o mundo diferente." Instrumental a análise dos circuitos informacionais ascendentes dinamizados por meio das rádios livres, a comunicação, segundo Sodré (1999), sinaliza para os espaço-tempos plurais e à proximidade entre os agentes, assim

(...) diz-se comunicação quando se quer fazer referência à ação de pôr em comum tudo aquilo que, social, política ou existencialmente, não deve permanecer isolado: isso significa que o afastamento originário criado pela diferença entre os indivíduos, pela alteridade, atenua-se graças a um laço formado por recursos simbólicos de atração, mediação ou vinculação (SODRÉ, 1999, p. 21).

que tem maior público diurno e a maior popularidade entre as grandes camadas urbanas". Segundo informações do IBGE de 2004, 89,3\% dos domicílios brasileiros possuíam rádio e $90 \%$ das pessoas entre 10 e 65 anos vivendo em cidades o escutavam diariamente. 
Por sua vez, Kosic (1976, p. 189) lembra que o modo de existência e a cotidianidade se interpenetram. Nesse meio, o trabalho é, ao mesmo tempo, base histórica e fronteira além da qual se demarca "o autêntico reino da liberdade."

Para abordar as manifestações dos que dinamizam o circuito das rádios livres em Campinas, entendidas como elementos de um circuito de cultura popular (CHAUÍ, 1987) possuidor de um alto componente de saber embutido que sinaliza para o que a ideologia dominante quer esconder, recordamos Santos (1994) e as noções de tempo lento e tempo rápido. O Ele explica que o tempo rápido é o tempo das firmas, das instituições e dos indivíduos hegemônicos e que os atores hegemonizados vivem no tempo lento. Segundo Santos (1994, p. 81), "a força dos fracos é seu tempo lento." Os coletivos do tempo lento são os que habitam áreas desprovidas de bens e serviços sociais, esquecidos pelos poderes públicos e, que, devido à sua imobilidade econômica diante da globalização, acabam por serem "mais velozes na descoberta do mundo", residindo aí a sua força (1994, p. 84-85). $\mathrm{O}$ autor enfatiza o poder dos homens lentos como agentes da mudança, sobre o que afirma,

Estamos descobrindo que, nas cidades, o tempo que comanda, ou vai comandar, é o tempo dos homens lentos. Na grande cidade, hoje, o que se dá é tudo ao contrário, a força é dos lentos e não dos que detém a velocidade (...). Quem, na cidade, tem mobilidade, e pode percorrê-la e esquadrinhá-la - acaba por ver pouco, da cidade e do mundo. Sua comunhão com as imagens, frequentemente pré-fabricadas, é a sua perdição. Seu conforto, que não desejam perder, vem, exatamente, do convívio com essas imagens. Os homens lentos, para quem tais imagens são miragens, não podem, por muito tempo, estar em fase com esse imaginário perverso e ir descobrindo as fabulações (SANTOS, 2004, p. 325).

Em nossa análise das rádios livres em Campinas enfatizamos o conflito e a cooperação entre os circuitos de informação ascendentes e descendentes no território, estes nutridos por demandas para além dos lugares, enquanto aqueles se fundam na proximidade entre os agentes e em uma vida de experiências compartidas. Segundo Santos (1994; 2004), os circuitos informacionais de cima para baixo, ou descendentes, são aqueles baseados em demandas externas, por vezes criadores de espaços rígidos, logo, portadores de lógicas e normas fundamentadas na obediência e na disciplina tal qual observado no circuito de rádio FM concessionária. Estes circuitos de cima para baixo chegam aos lugares dinamizados por uma integração funcional e um maciço sistema de objetos técnicos, cuja função pode ou não ser subvertida. Por outro lado, os circuitos 
informacionais ascendentes, ou de baixo para cima, se referem à parte dos lugares que insurge em ações cotidianas de interesse comum, portadores do novo, predicado de grande parte do circuito em torno das emissoras de rádio não concessionárias.

Entendemos que a partir dos microcircuitos em torno das rádios livres difundese uma comunicação de baixo para cima com discurso e linguagem instituintes, elementos essenciais nas ações dos homens do tempo lento, sinal do seu mundo vivido. Assim, eis um dado que, de acordo com a nossa ótica, deve nortear as discussões sobre a democratização dos meios de informação, a saber, "às classes dominadas caberá o papel fundamental nas transformações da visão do jornalismo pela população" (ABRAMO, 2003, p. 49), uma vez que às elites cabe o papel de dirigentes dos grandes meios de informação ${ }^{7}$.

\section{Periferias e rádios livres na Região de Campinas: o território e a difusão da resistência}

Variáveis como conflito, imposição e resistência se mostram fortemente presentes no que tange à dinâmica das rádios livres em Campinas. Na cidade, durante o mandato da prefeita Izalene Tiene (PT), entre os anos de 2001 e 2004, muita discussão foi gerada em torno de um projeto de municipalização das concessões que legalizaria as rádios locais não concessionadas. A proposta era montar um conselho municipal de comunicação, de modo a avaliar pedidos de concessões e movimentar os quase cinquenta pedidos de outorga, então parados desde 1998 na ANATEL. O projeto acabou sendo cassado ${ }^{8}$ e um cadastro das emissoras não concessionadas e sob a promessa de legalização durante as discussões da proposta de municipalização das concessões, suscitou um guia para

\footnotetext{
${ }^{7}$ Abramo (2003) detalha os mecanismos utilizados pela grande mídia do país para manipular a informação, demonstrando que os meios de informação se comportam como entes políticopartidários, devendo ser considerados como tal, daí a centralidade da população como formadora de um novo jornalismo. A transformação viria em três planos: "Num primeiro plano, as classes politicamente dominadas tenderão, cada vez mais, a desmistificar o jornalismo e a imprensa (...). Passarão a intensificar sua postura crítica (...). No segundo plano, tenderão a passar a um nível superior de defesa e contra-ataque em relação à imprensa" (ABRAMO, p. 49). E, sobre o terceiro plano, "Se os órgãos de comunicação passaram de instituições da sociedade civil a instituições da sociedade política, não haverá mais razão para aceitá-los como instituto de direito privado e deverão se transformar em institutos de direitos públicos" (p. 50).

${ }^{8} \mathrm{Com}$ a cassação do projeto, continuou e intensificou-se o fechamento das rádios livres que eram 96 em 2004 na cidade de Campinas. Essas operações de fechamento em 2005, comandadas pela ANATEL e pela Polícia Federal, foram chamadas de Ondas Piratas (Jornal Correio Popular, 17/06/2005) e resultaram no fechamento de uma dezena de rádios.
} 
apreensões. Os artigos de jornais de Campinas ${ }^{9}$ que tratam da localização de rádios não concessionadas apreendidas pela Polícia Federal indicam uma topologia diferente daquela observada pelo o circuito de emissoras de rádio FM concessionadas de Campinas (Figura 1). O caso campineiro demonstra a necessidade de uma informação distinta dos grandes meios, mostra, portanto, uma demanda comunicacional das periferias. Observa-se que a grande parte das emissoras não concessionadas apreendidas (13 de um total de 16 emissoras) se localizavam no chamado "eixo da pobreza" (CANO; BRANDÃO, 2002) da Região de Campinas, aglomeração fruto de um processo de periferização da metrópole e que se estende ao sul da Rodovia Anhanguera.

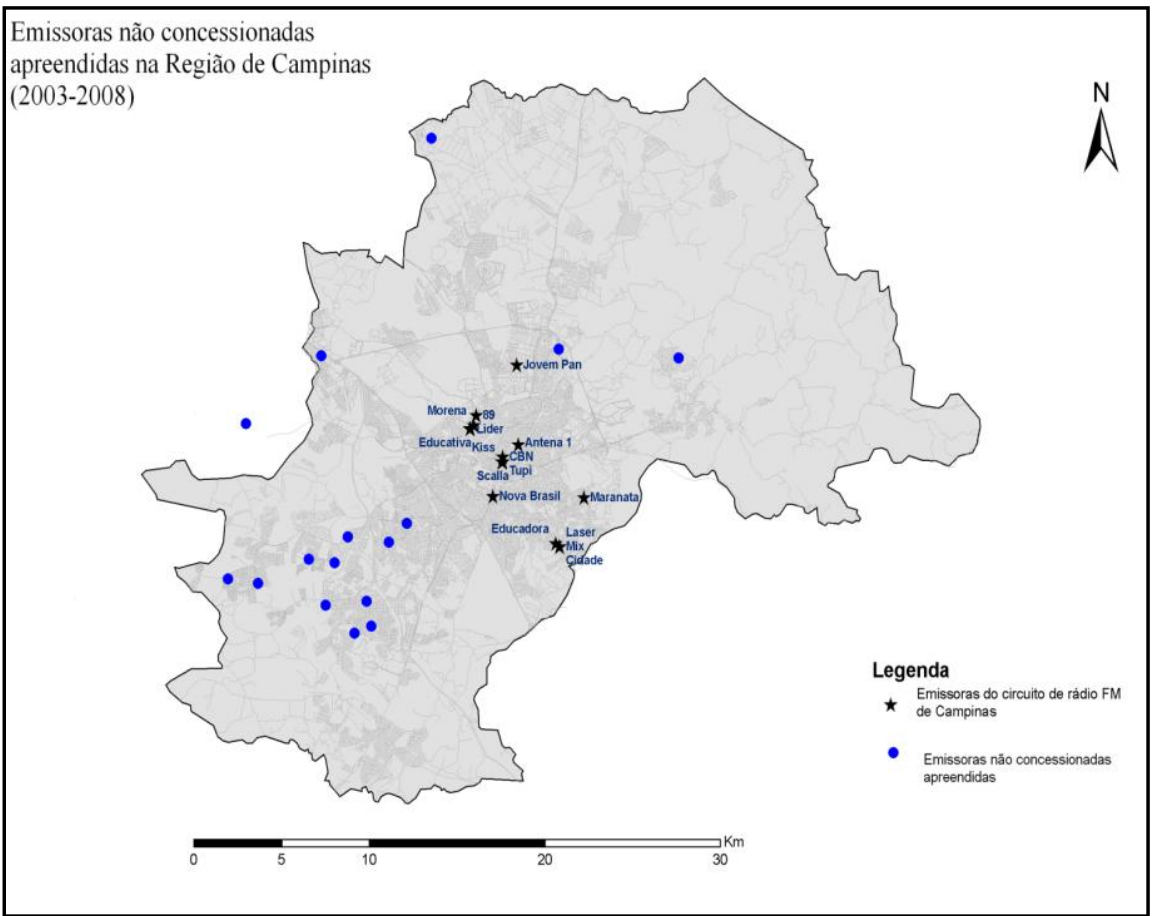

Figura 1:

Topologia

do circuito

de rádio

FM em

Campinas:

emissoras

não conces-

sionárias

apreendidas

na Região

de

Campinas

(2003-

2008).

Elaboração:

Cristiano

Nunes

Alves.

Cartografia:

Daniel

Henrique

Cândido.

\footnotetext{
${ }^{9}$ Os artigos utilizados como fonte foram: JORNAL CORREIO POPULAR, 22 de dezembro de 1995. Motta afirma que emissoras serão legalizadas; JORNAL CORREIO POPULAR. 12 de novembro de 1998. PF fecha rádio pirata em Limeira; DIÁRIO DO POVO. 12 de agosto de 2000. Operação fechamento: polícia tira emissoras do ar sob alegação de que a lei que as regulamenta ainda não está em vigor; DIÁRIO DO POVO. 19 de agosto de 2000. Associação briga com a Anatel; JORNAL CORREIO POPULAR. 15 de agosto de 2002. Fiscalização lacra rádios clandestinas; JORNAL CORREIO POPULAR. 11 de setembro de 2003. Anatel lacra transmissor de rádio comunitária; JORNAL CORREIO POPULAR. 31 de abril de 2005. Polícia tira rádio pirata do ar; JORNAL CORREIO POPULAR. 17 de junho de 2005. Seis rádios piratas são fechadas em Campinas.
} 
A ação da Polícia Federal e de agentes da Anatel vem causando revolta pela imposição de procedimentos abusivos: "a polícia muitas vezes chega pelo telhado das casas com enxadas e fecha a rádio" afirma a militância local*.

Estima-se que sejam, hoje, mais de 150 rádios não concessionadas na Região Metropolitana de Campinas, correspondentes em seu conjunto à segunda audiência na urbe campineira ${ }^{10}$, mesmo com a grande repressão de órgãos como a Anatel e a Polícia Federal sob a batuta dos grandes meios de informação - dinamizadores de espessos fluxos de informação descendentes - numa espécie de cruzada anti"ilegais". A rádio CBN, pertencente ao grupo Globo, por exemplo, já havia noticiado o fechamento da rádio Tropical em Sousas, antes mesmo de o fato ocorrer, em 2007, afirmam militantes locais*. A Radiocamp, órgão ligado ao circuito de rádio FM concessionado da região, disponibiliza um e-mail para denunciar as emissoras não concessionadas e apresenta todo um discurso dito democrático:

Faça um serviço à sociedade, denuncie a pirataria no 'dial'. Como pode Campinas, um polo tecnológico (...) que sempre auxiliou a Anatel, ser uma das maiores vítimas da pirataria radiofônica? A ponto de boa parte dessas rádios divulgarem no ar endereços e telefones. É ou não exemplo de terra sem lei? (www.radiocamp.org).

Segundo Lopes (1997, p. 288) há um "problema da censura exercida em nível privado, de difícil constatação e até mesmo conhecimento pela sociedade", fenômeno que é gerenciado pelas grandes empresas de informação, as quais comandam o rádio concessionado. Desse modo, indagamos de que vale o Artigo 221 do Código Brasileiro de Telecomunicações, o qual estabelece entre os princípios na produção e programação do rádio e da TV a "promoção da cultura nacional e regional e estímulo à produção independente" e a "regionalização da produção cultural, artística e jornalística, conforme percentuais estabelecidos por lei’"?

Ao que tudo indica, o estabelecido pela norma é cumprido justamente por quem dela escapa. Uma série de ações nas rádios livres campineiras endossa o argumento. Glória*, uma das militantes da comunicação em Campinas, há onze anos se dedica a uma rádio livre comprometida com a música de raiz, um dos resquícios da cultura caipira e cujo arquivo conta com cerca de $1000 \mathrm{CDs}$. Na área de abrangência da emissora mora grande contingente de migrantes, em especial do oeste paulista e do norte do Paraná, criados nas tradições caipiras, centrados em

\footnotetext{
${ }^{10}$ Fonte: IBOPE - Instituto Brasileiro de Opinião Pública, 2008.
} 
costumes familiares oriundos de um modo de vida campesino (MARIANO, 2005). Emocionada, a comunicadora lembra* que a origem dessa música não lhes é estranha "Temos o direito de reivindicar o que é melhor para nós, uma música que está no nosso sangue, que corre na veia e faz parte da vida da gente". Trata-se de um repertório ligado ao lugar, pois constituído de relações reais nas quais a música e o circuito não são inventados por um ou outro, mas vividos por todos, uma construção coletiva acima de tudo.

Por outro lado, a diluição do gênero musical de raiz, resulta, entre outros, no "sertanejo classe A", repertório de emissoras campineiras concessionadas como a Laser, a Tupi e a Líder: um golpe na autoestima caipira, confundida com valores que não são os seus, afirmam os militantes comunicacionais da cidade*.

Numa outra rádio da periferia de Campinas, existente há doze anos, fatos ocorridos no bairro são discutidos entre a população, responsável pela elaboração da grade de programação. Anúncios locais vinculados à manutenção desta rádio livre são estipulados pela população, o que estimula o pequeno comércio*. Nesse momento do circuito manifesta-se o "mercado socialmente necessário" (RIBEIRO, 2005) animado por "uma vida de relações resistente e tenaz" (p. 107) que, pautado em trocas simbólicas, tem potencial para resistir ao mercado hegemônico e o faz, ou seja, resiste.

Observa-se, desse modo, como por meio da dialética entre o saber, a experiência diária vivida nos lugares e o adensamento de circuitos informacionais ascendentes, as rádios livres participam ativamente da organização do entorno, engendrando fixos e fluxos geográficos relacionados ao mundo vivido dos sujeitos periféricos urbanos. Ocorrem, a partir da ação das rádios livres, consequências territoriais nas esferas política, cultural e econômica dos lugares.

A proposta desses veículos alternativos evidencia-se, ainda, através do ocorrido numa rádio livre dirigida por um evangélico, porém laica em sua programação, que está em funcionamento na cidade desde 2002. Na emissora, explica um de seus militantes*, o critério não é religioso ou mercadológico, a condição é o conteúdo da programação (música ou informação) representar de alguma maneira a diversidade do lugar. Desde grupos de rap até manifestações de ritmos de umbanda têm lugar na emissora, que ainda organiza encontros de violeiros em espaços públicos do bairro. Nesse caso a repercussão espacial das rádios livres se dá por meio da sinergia entre o hábito cotidiano dos moradores e a informação musical, redundando, entre outros, em eventos musicais e na busca por demandas estéticopolíticas que possam dizer mais sobre a vida das pessoas.

A inclusão de um conteúdo ascendente na programação das rádios livres, ou seja, baseado nas demandas dos lugares e dos seus sujeitos, não é mais ampla pelo fato da produção alternativa aos grandes meios ser pouco acessível a tais 
emissoras, implicação que tem sido gradativamente minimizada pelo uso da internet em especial nos últimos anos: os CDs estão muito caros e os genéricos, em sua grande maioria, representam um repertório padrão, com algumas exceções. Para quem movimenta essas rádios, o repertório é composto por discos de conhecidos, coleções pessoais e mais um ou outro título. Neste caso, a relação entre objetos e sistemas técnicos e bens culturais norteiam o olhar para a produção de informações lugarizadas via circuitos ascendentes por meio das rádios livres.

Um dos problemas para o espraiamento de um repertório lugarizado, é que as comunitárias e os selos (gravadoras) menores pouco se articulam ${ }^{11}$, com exceção de alguns selos produtores de rap ${ }^{12}$, música da chamada cultura das ruas - o hip hop composto ainda pelo break (dança) e pelo grafite (expressão visual).

Não por acaso, asseveramos que uma maior ligação entre as rádios livres e a produção musical de Campinas e do seu entorno, é dada nos circuitos ligados ao rap. Estimamos que metade das emissoras livres campineiras difundam a produção fonográfica local da música da cultura hip hop. Em inventário realizado por nós em quinze cidades da RMC (ALVES, 2005), averiguamos que onze delas tiveram o rap transmitido por rádios livres, em todos os casos, com abertura para a produção local ${ }^{13}$.

Na Região de Campinas, constatamos* que as rádios livres tiveram uma importância central para a divulgação da cultura hip hop em Santa Bárbara D' Oeste, assim como ocorreu também em outras localidades. O município chegou a abrigar quatro rádios livres ligadas ao rap; em 2005 apenas duas das emissoras estavam em operação, ambas na zona leste, área conurbada ao município de Americana. Uma delas, a Rádio Onda Azul, bastante ouvida pelos jovens do entorno, funcionou desde o final da década de 1990 até meados dos anos 2006, e manteve ao longo deste tempo destaque para o rap em sua programação.

Outra situação que merece relevo é a da cidade de Hortolândia, conurbada à Campinas, e cuja alta densidade populacional abrigada numa pequena extensão territorial suscita que mesmo os transmissores de potência reduzida alcancem, de modo eficiente, uma série de bairros. Hortolândia, em meados dos anos 2000, contava com uma gama de rádios livres difundindo o rap local, entre as quais a Rádio Cidade e o seu programa o Rap treme o Chão, de grande audiência entre os jovens das adjacências*.

\footnotetext{
${ }^{11}$ A militância local afirma*, nesse sentido, que trabalha na criação de um banco de dados de produção alternativa e de grupos da Região.

${ }^{12}$ Destaca-se a iniciativa do cantor de rap GOG, com a distribuição de uma cota de dois mil exemplares de seu álbum Tarja Preta de 2004, em rádios livres.

${ }^{13}$ As cidades inventariadas onde constatamos a articulação do rap com emissoras livres foram: Americana, Campinas, Cosmópolis, Hortolândia, Indaiatuba, Jaguariúna, Monte Mor, Paulínia, Santa Bárbara D’Oeste, Sumaré e Valinhos.
} 
A empiria em torno das rádios livres ligadas ao hip hop destaca como a radiodifusão fundada nas demandas do entorno provocou a reorganização desses subespaços, que se tornaram abrigo para uma série de espessuras culturais, manifestas em batalhas de break, grafitagens, ação de grupos de rap, entre outras.

Cumpre destacarmos, além disso, que o conjunto das rádios não concessionadas incluiria as rádios comunitárias difusoras de informação ascendente, pois estão fundadas na realidade dos lugares, e outro tipo de rádio mais ligada à reprodução das práticas e dos conteúdos do circuito comercial, chamadas de "picaretárias"14, entre os militantes da comunicação. Parcelas destas rádios estão ligadas a políticos e igrejas e, por isso, são as que têm mais chances de serem legalizadas, "mesmo não cumprindo" (quem sabe, o termo seja "por não cumprirem") os requisitos para serem consideradas comunitárias de acordo com uma proposta comunicacional.

Daí Jerry de Oliveira*, coordenador da regional Campinas da ABRACO, explicar que nem todas as rádios sem autorização merecem a denominação de comunitária, da mesma maneira que existem rádios comunitárias legalizadas. De acordo com a ABRACO, uma rádio para ser determinada comunitária deve ter cinco funções, a saber: 1) ser participativa e estimular a comunicação entre as pessoas; 2) estar ligada à cultura popular; 3) ser laica e em prol da diversidade; 4) ser organizativa, convocando a população; e 5) ser educativa e atuar no cotidiano do coletivo.

A ABRACO conta com equipamentos para instalação de rádio comunitária em caso de fechamento; trata-se de uma poupança popular a ser retirada em caso de ação da Polícia Federal. Essa emissora reserva é criada pelos próprios associados, "se fecharem uma emissora hoje, amanhã abrimos outra" esclarece Jerry*. Vê-se como os sistemas técnicos informacionais são indispensáveis ao intento comunicacional, nesse caso conclamados para dar potência e fluidez à reorganização dos lugares a partir das rádios livres.

Entre os militantes locais, a postura é de diálogo e conscientização dos que movimentam as não concessionadas, algumas delas com o tempo adquirem a condição de rádios comunitárias. Ora, falamos da espacialização de um processo informacional no qual se impõem formas-conteúdo ascendentes, maleáveis, frutos da troca de experiências no cotidiano da urbe.

$\mathrm{O}$ apoio à instalação desses veículos é justamente nas áreas periféricas. Entre outras iniciativas, a ABRACO transmite diariamente um programa em rede via

\footnotetext{
${ }^{14}$ Alusão ao termo "picareta", que na linguagem popular faz referência a pessoas ou atividades duvidosas, alicerçadas em ações ligadas à má índole ou ao engodo. Lembremo-nos do circuito que se forma em torno das igrejas, movimentado pelas próprias emissoras, por estúdios especializados na elaboração de conteúdo e todo um mercado gospel farto em produtos e possibilidade de difusão. Em Campinas, destaca-se, entre outros, o caso do político Salvador Zimbaldi e a sua rádio ligada à "renovação carismática católica."
} 
internet com duração de dez minutos. Em Campinas o único lugar onde o programa não pode ser acessado devido a problemas técnicos ${ }^{15}$ é no Parque Oziel, uma das maiores ocupações do Brasil, no entroncamento entre as Rodovias Anhanguera e Santos Dumont. Por isso, um morador vai até a sede da ABRACO, no centro da cidade, buscar o CD com o programa todos os dias, o que nos dá ideia da importância desse meio de informação para o lugar.

Entendemos que a postura de vanguarda desses militantes comunicacionais confronta visceralmente todas as esferas de controle a partir de concepções estéticas e políticas que ecoam na geografia dos lugares e no seu mercado. Este conhecimento possibilita que se saibam quais os caminhos em direção ao projeto que se procura. Trata-se de uma informação a respeito do outro: quem pode fazer? E de si mesmo: como posso fazer? Princípios de solidariedade.

\section{Considerações Finais}

A radiodifusão chega a todos os lugares, mas seu efeito é diferenciado. Ela interage e rivaliza com uma série de forças na cidade: o caldo de culturas, o lugar dos encontros. A análise das rádios livres campineiras evidencia que há resistência, e outras formas-conteúdo se difundem, questionando-se, assim, uma paisagem sonora (SCHAFER, 1997 [1977]) fundada em um repertório médio e uma psicosfera, (SANTOS, 1996), a esfera das ideias e das paixões ajustadas ao pensamento racionalizante.

Ora, a empiria analisada indica como a dinâmica das rádios livres campineiras contribui para a reorganização dos lugares difundindo informações intrínsecas às suas realidades, destacando seus anseios, necessidades e contradições, erigindo circuitos informacionais ascendentes que reverberam nas diversas esferas da vida cotidiana.

Tais emissoras funcionam como "nós" de uma rede comunicativa, difusora de informações ascendentes, articulando diversos bairros e agentes em torno de práticas e conteúdos distintos daqueles oferecidos pelos grandes meios de informação. Estes "nós" concentram e difundem informações que são condição e resultado de um leque de experiências corporificadas no próprio cotidiano da metrópole. Trata-se de fixos fixados de grande poder, pois portadores do movimento intrínseco às ondas sonoras, cujas mensagens aglutinam agentes

\footnotetext{
${ }^{15}$ Pontuamos que, em Campinas, às rádios livres somam-se outros serviços comunicacionais fornecidos pelos próprios moradores, como provedores de internet com sistemas alternativos aos modelos da Companhia Telefônica ou da Vírtua, empresas do setor. Tais serviços atingem dezenas de bairros por metade do preço cobrado pelas grandes companhias.
} 
periféricos em torno de demandas inerentes à sua vida de relações. Tais mensagens se manifestam, seja em um repertório musical com abertura para a produção local na abordagem dos problemas da urbe, ou na organização de eventos culturais.

$\mathrm{Na}$ ação das rádios livres condensam-se os questionamentos quanto ao monopólio dos meios de informação de massa, veículos operantes de acordo com formatos e prerrogativas instrumentais aos desígnios de agentes que pensam e utilizam o território como um recurso.

A empiria em torno das rádios livres na região de Campinas, a um só tempo, indica, ainda, uma demanda informacional das periferias da cidade e demonstra o papel de grande parte dessas emissoras na articulação entre bairros e no fortalecimento da cultura popular por meio da difusão de músicas ou informações baseadas nos hábitos dos lugares. Na medida em que promovem a produção cultural lugarizada e independente, são justamente as rádios não concessionadas, portanto "ilegais", as maiores cumpridoras do previsto pela legislação, na qual não são contempladas. Eis a assimetria entre a norma e a organicidade dos lugares, condicionantes e condicionados pelas rádios livres.

Vemos na mídia alternativa - seja em jornais, fanzines, panfletos, rádios livres, cartazes, entre outros - uma composição que merece maior atenção e pode nos dar importantes indícios sobre o funcionamento dos lugares, desvelando como a partir da comunicação entre os homens lentos, pode se produzir uma outra versão dos fatos.

A efervescência na constante ação dos militantes da comunicação nos faz afirmar que os homens do tempo lento não agem em baixa velocidade, apenas negam a temporalidade imposta pela racionalidade técnica e econômica. Consideramos esses sotaques locais e contestatórios o encontro entre a informação e o cotidiano, cerne dos saberes, espessuras de informações ascendentes dos lugares. Um tipo de conhecimento insurgente, edificado sobre os microcircuitos em permanente mutação do circuito sonoro, abrigo potencial da resistência dos lugares.

A resistência se cristaliza nos eventos reivindicatórios de diversas naturezas na Região de Campinas: no protesto dos camelôs que reclamam o seu lugar no centro da cidade; nas manifestações dos "perueiros" do transporte alternativo, que por vezes interromperam o tráfego; nas passeatas das lideranças de bairro contra a precariedade da infraestrutura urbana ou nos assentamentos do MST nos arredores da cidade. Falamos de um conjunto de vozes.

Tomando como um dado os encontros e as comunicações possíveis na metrópole por meio de circuitos informacionais ascendentes, propomos o debate acerca de quais os caminhos para que o conjunto dessas vozes se torne uma voz em conjunto: respeitando os sotaques da diversidade, mas em prol de objetivos 
comuns. Acreditamos que nessa voz, assim constituindo a verdadeira maioria, estaria a proposta de outro projeto urbano, mais igualitário.

\section{Bibliografia}

ABRAMO, P. (2003) Padrões de manipulação na grande imprensa. São Paulo: Editora Fundação Perseu Abramo.

ALVES, C. N. (2005) O circuito hip hop na Região Metropolitana de Campinas: para que o território e a arte digam algo sobre nossas vidas. Monografia (Graduação em Geografia) - Instituto de Geociências da Unicamp. Campinas.

ALVES, C. N. (2008) O circuito sonoro: a radiodifusão FM e a produção fonográfica em Campinas-SP. Dissertação (Mestrado em Geografia) - Instituto de Geociências da Unicamp. Campinas.

AMAYO, G. C. (1992) Rádio Público na Cidade de São Paulo. Tese (Doutorado em Comunicação Social) - Escola de Comunicação e Artes da Universidade de São Paulo. São Paulo.

ANDRIOTTI, C. D. (2004) O movimento das rádios livres e comunitárias e a democratização dos meios de comunicação no Brasil. Dissertação (Mestrado em Ciências Sociais) - Instituto de Filosofia e Ciências Humanas da Unicamp. Campinas.

CANO, W.; BRANDÃO, C. A. (2002) A região Metropolitana de Campinas: urbanização, economia, finanças e meio ambiente. Vols. 1 e 2. Campinas-SP: Editora Unicamp.

CARNEY. G. O. (1990) Geography of music: inventory and prospect. Journal of Cultural Geography, n 10. pp. 35-48.

.; NASH, P. H. (1996) The seven themes of music geography. The Canadian Geographer, 40, ${ }^{\circ}$ 1. pp. 69-74.

CHAUDOIR, P. (2003). Spectacles, fêtes et sons urbains. Géocarrefour, $\mathrm{n}^{\circ}$ 78. pp. 167-172.

CHAUÍ, M. (1987) Conformismo e resistência: aspectos da cultura popular no Brasil. São Paulo: Brasiliense.

CÓDIGO BRASILEIRO DE TELECOMUNICAÇÕES. Lei no 4.117, de 27 de agosto de 1962.

COHN, G. (1973) Sociologia da comunicação - teoria e ideologia. São Paulo: Pioneira.

FRIEDMANN, G. (1968) Sete estudos sobre o homem e a técnica. São Paulo: Difel.

GEERTZ, C. (2003) O saber local: novos ensaios em antropologia interpretativa. 
Petrópolis: Vozes.

HAGERSTRAND, T. (1952) The propagation of innovation waves. Lund Studies in Geography.

Lund:

Lund : The Royal University of Lund.

KOSIC, K. (1976) Dialética do Concreto. Rio de Janeiro: Paz e Terra.

LOPES, V. M. O. N. (1997) $O$ direito à informação e as concessões de rádio e televisão. São Paulo: Editora Revista dos Tribunais.

LUCCA, S. (2002) O produto musical nas rádios brasileiras e aspectos de sua influência: um panorama atual paulistano. Dissertação (Mestrado em Comunicação), Universidade de São Paulo. São Paulo.

MACHADO, A.; MAGRI, C.; MASSAGÃO, M (1987) Rádios livres: a reforma agrária no ar. São Paulo: Brasiliense.

MAGNONI, A.; et al. (1999) O rádio digital avança no interior de São Paulo. In: BIANCO, N. R. del; MOREIRA, S. V. (orgs.). Rádio no Brasil: tendências e perspectivas. Rio de Janeiro/Distrito Federal: UERJ/UNB. pp. 41-60.

MARIANO, N. de F. (2005) Herdeiros da rusticidade a cultura caipira no município de Jaú (SP). Geousp, n 17. pp. 43-59.

MATTELART, A. (2002) A globalização da comunicação. Florianópolis: EDUSC. MORIN, E. (1979) Cultura de massas no século XX: o espírito do tempo. Volume 1- Neurose. Rio de Janeiro: Forense Universitária.

RIBEIRO, A. C. T. (1991) Matéria e espírito: o poder (des)organizador dos meios de comunicação. In: PIQUET, R.; RIBEIRO, A. C. T. Brasil. Território da desigualdade. Rio De Janeiro: Zahar. pp. 45-56.

. (2005) Território usado e humanismo concreto: o mercado socialmente necessário. In: SILVA, C. et al. (2005). Formas em crise: utopias necessárias. Rio de Janeiro: Arquimedes Edições. pp. 93-111

ROMAGNAN, J. M. (2000) La musique: un terrain nouveau pour les géographes. Géographie et Cultures, $\mathrm{n}^{\circ}$ 36. pp. 107-126.

SÁNCHEZ, J. E. (1992). El espacio y la innovacion tecnológica. In: Espacio, economia y sociedad. Madrid: Siglo XXI - Sintesis. pp. 263-319. SANTOS, M. (1994) Técnica, espaço e tempo. São Paulo: Hucitec.

. (2006 [1996]) A natureza do espaço: técnica e tempo, razão e emoção. São Paulo: Hucitec.

. (2006). Por uma epistemologia existencial. In: ARROYO, M. et al. Questões territoriais na América Latina. São Paulo: CLACSO. pp. 2-8.

SANTOS, M.; SILVEIRA, M. L. (2001). O Brasil: território e sociedade no início do século XXI. Rio de Janeiro: Record.

SCHAFER. R. M. (1977). A afinação do mundo - uma exploração pioneira pela história passada e pelo atual estado do mais negligenciado aspecto do nosso 
ambiente: a paisagem sonora. São Paulo: Unesp.

SILVA, A. B. (2010) A cidade de São Paulo e os círculos de informações. Ciência Geográfica. Ano XIV, vol. XIV, nº1, janeiro/dezembro. Bauru: AGB. pp. 24-30.

SMITH, N. (1984) Desenvolvimento desigual: natureza, capital e a produção do espaço. Rio de Janeiro: Bertrand Brasil, 1988.

SODRÉ, M. (1976) A comunicação do grotesco: um ensaio sobre a cultura de massas no Brasil. Petrópolis-RJ: Vozes.

SODRÉ, M. (1999) Reinventando a cultura: a comunicação e seus produtos. Rio de Janeiro: Vozes.

TELLA, M. A. (2000) Atitude, arte, cultura e auto conhecimento: o rap como voz da periferia. Tese (Doutorado em Ciências Sociais) - Departamento de Ciências Sociais, Pontifícia Universidade Católica - PUC. São Paulo.

TRAGTENBERG, L. (1991) Artigos musicais. São Paulo: Perspectiva.

WISNIK, J. M. (1989) O som e o sentido: uma outra história das músicas. São Paulo: Cia. das Letras. 